\title{
Closure of Cardiac Atrial Septum
}

National Cancer Institute

\section{Source}

National Cancer Institute. Closure of Cardiac Atrial Septum. NCI Thesaurus. Code C99939.

Repair of atrial septum. (ACC) 